\title{
Verbal stress and heart-rate in humans exposed in groups 1,2
}

\author{
W. F. ANGERMEIER AND J. B. PHELPS, FLORIDA PRESBYTERIAN COLLEGE \\ H. H. REYNOLDS, ARL, HOLLOMAN AFB, NEW MEXICO
}

Twenty-eight human Ss were exposed to a line judging problem individually and in groups of twos and threes. E applied verbal harassment in all tests at the same intervals. Heartrate was monitored throughout testing. It was found that the heartrate of $S s$ exposed individually was significantly higher than that of Ss exposed in groups of threes during the 10-sec intervals following verbal harassment. This socially mediated reduction of an ANS response to stress confims the findings of studies in which animals were tested in a similar experimental format.

Numerous studies have investigated the influence of exposure to stress upon various autonomic parameters. Lazarus, Speisman, \& Mordkoff (1963) have shown that there is evidence of a generalized autonomic reaction to stress when appropriate analytical methods of correlation are utilized. Wolf (1966) found that physical tolerance of the effects of stress upon the ANS can be achieved. One method by which such a tolerance can be realized in rats has been demonstrated by Angermeler, Philhour, \& Higgins (1965). The authors of this study concluded that stress can be considerably reduced when the organism is exposed to the stressful stimulus conditions in the presence of other organisms of his species. The socially mediated reduction of autonomic response to stress in monkeys was described by Mason (1960).

This study sought to investigate a socially mediated reduction of one autonomic response to verbal stress in humans.

\section{Subjects}

Ss were 28 Negro males and two Caucasian males between the ages of 15 and 17 years. All Ss were experimentally naive and came from underprivileged social environments.

Apparatus

The apparatus used in this study consisted of a heart-rate telemetry system, two solid sllver compression type electrodes, a servo recorder, a projection screen, a TV camera and compatible monitor, and an audio amplifier and microphone with a 6 in. speaker. All apparatus is commercially available. Procedure

Testing took place in a small room divided into two equal areas by a fixed wall to wall partition and equipped for controlled lighting. $S$ was seated in one area (A) while monitoring of all measures took place in the other area (B). S was directed into area $A$ and seated in a padded swivel type chair. After 2 min of rest, S's pre-experimental pulse was measured man- ually. Then the projection screen, displaying five horizontal lines centered on it, was revealed to S. All lines were $1.5 \mathrm{in}$. wide, uniformly spaced from each other, and constructed of industrial tape. The lines varied in length from 6 to 25 in. The TV camera and the monitor were activated at this time. $E$ then instrumented $S$ by attaching the electrodes ventrally and to the right of S's heart region. S was instructed to seat himself comfortably and exercise minimial bodily movements. $E$ then left area $A$.

After heart rate, measured via telemetry, reached the pre-experimental range ( \pm 3 beats/min), E gave $S$ instructions over the microphone. The essence of these instructions was for $S$ to look at the lines on the screen and to judge their lengths in in., one at a time, from top to bottom. On Lines 2, 3,4, and 5, E informed $S$ that he had made a "big mistake" and $E$ requested $S$ to look at the respective lines once more to reevaluate his original estimates. These remarks were made by $E$ regardless of S's accuracy of judgment. The Ss which made their judgments in the presence of other Ss were given the same verbal harassment and, additionally, told that they may ask their "friends" for help, if they so desired. Another $E$ observed the servo recorder and operated the event marker to exhibit heart rate graphically throughout (a) presentation time, (b) rest intervals-uniformly 15 sec-, and (c) time periods during which remarks by $E$ occurred. Fourteen Ss made the experimental judgments alone (G1), 10 Ss did so with one social partner present (G2), and six Ss were tested in the presence of two social partners (G3).

Results

The raw data consisted of the number of heartbeats during the 10 sec intervals which followed verbal harassment. These raw data were converted into percentage of pre-experimental heart rate increases or decreases. The group means for these percentage increases or decreases were as follows: single Ss (G1) $=+13.2$ percent; groups of two $(G 2)=+17.9$ percent; groups of three $(G 3)=+5.4$ percent. The number of percentage heart rate increases and decreases in each group were analyzed by the Fisher Exact Probability Test, suggested by Siegel (1956). In the comparison between G1 and G2, the value of $D$ was 6 for $A+B$ $=13, C+D=6$, and $B=13$. This value was not significant. Comparing $G 1$ and G3, the value of $D$ was 6 for $A+B=13, C+D=10, B=13$, and was significant at the .025 level. The final comparison between the $\mathrm{G} 2$ and G3 groups yielded a value of $D=6$ for $A+B=6, C+D$ 
$=10, B=6$, and was again not significant. The raw data showed that the increase in heart rate was highest for G2. From observations via the TV monitoring system it was apparent that competitive factors were present in this situation. There was often doubt exhibited by the G2 Ss in what his social partner believed to be a correct judgment, and also considerable embarassment seemed to result from being in error. These factors did not appear when two social partners were present (G3). The comparison between G2 and G3 failed to reach statistical significance primarily because of the limited number of Ss in the G2 condition. Discussion

The important findings of this study seem to be the similarity between the human data presented here and animal data reported earlier(Angermeier, Philhour, \& Higgins, 1965). Although it may not be appropriate to make direct comparisons between the two studies, it is nevertheless obvious that in both cases the presence of a certain number of social partners seems to have inhibited the indicators of the emotional response under consideration. In the rat study as well as in the human study, the highest rate of responding was obtained for Ss tested with one social partner present, and the group effect was observed only when the group consisted of at least three Ss. In another study with rats (Angermeier, 1966) it was shown that bodily contact between the experimental animal and his social partners was absolutely essential to demonstrate the group effect of inhibition mentioned above. At the human level, where facial expressions, gestures, and other symbolic indicators of interpersonal relationships are prominent, spatial separation in the testing situation had apparently no effect upon the results obtained. Since considerable individual variations were observed, it is possible that this method may aid other diagnostic tools in determining with whom one can feel comfortable in various real life situations.

\section{References}

Angermeier, W. F. Versuche über die Furcht bei Tieren. Wissensch. Zeitschr. Univ. Leipzig, 1966, 15, 467-470.

Angermeier, W. F., Philhour, P., \& Higgins, J. Early experience and social grouping in fear extinction of rats. Psychol. Rep., $1965,16,1005-1010$.

Blatt, S. J. Patterns of cardiac arousal during complex mental activity. J. abnorm. soc. Psychol., 1961, 63, 272-282.

Lazarus, R. S., Speisman, J. C., \& Mordkoff, A. M. The relationship between autonomic indicators of psychological stress: heart-rate and skin conductance. Psychosom. Med., 1963, 25, 19-30.

Mason, W. A. The effects of social restriction on the behavior of rhesus monkeys: I. Free social behavior. J. comp. physiol. Psychol., 1960, 53, 582-589.

Siegel, S. Nonparametric statistics. New York: McGraw-Hill, 1956. Wolf, S. Emotional stress and the heart. J. Rehabil.. 1966, 32, 4245.

\section{Notes}

1. This research was sponsored by contract AF 29 (600)-5135 between the Aeromedical Research Laboratory, Holloman AFB, New Mexico and Florida Presbyterian College.

2. A more detailed report is available from the authors upon request. 